\title{
Reorganização Geral do Serviço de Documentação do Estado da Guanabara
}

\section{Araujo Cavalcanti}

\begin{abstract}
A transformação da Prefeitura do Distrito Federal no atual Estado da Guanabara, em conseqüência da mudança da Capital Federal para Brasilia, foi um acontecimento histórico da maior significação e importância, para os destinos da Federação, em 1960. A interiorização da Capital, longamente esperada pelo Povo Brasileiro, levada a efeito no Planalto Central pelo Presidente Juscelino Kubitschek, constituitu uma iniciativa de repercussões benéficas e profundas em todos os sletores da vida nacional. Tanto na órbita politico-administrativa da Nação, como no campo das atividades econômicas, sociais e culturais, sente-se o impacto dos gingantescos empreendimentos decortentes da construção dle Brasilia. Como é natural, as transformações mais profundas e decisivas ocorreram, simultâneamente, no âmbito da antiga Prefeitura do Distrito Federal, elevada à categoria de Estado da Guanabara como a mais nova Unidade Federativa. Modificações radicais lestão se operando na estrutura e funcionamento dos Serviços Públicos do Estado recém-instituido, cujos problemas de govêtno e administração têm desafiado a capacidade dos técnicos, das autoridades e dos estudiosos, em geral, dêsses problemas. A Revista do Serviço Público déeu início à divulgação de vátios trabalhos, de mérito e utilidade incontestáveis, focalizando os problemas acima mencionados. Dando prosseguimento à publicação dessas contribuições, a Revista do Serviço Público, transcreve, na presente edição, o estudo elaborado pelo Prof. Araujo Cavalcanti - primeiro de uma Série - a respeito da "Reorganização Geral do Serviço de Documentação do Estado da Guanabara". Em seguida, também do mesmo Autor assiduo colaborador desta Revista cujos trabalhos são do
\end{abstract}


conhecimento dos leitores e dos especialistas em assuntos de Administração, Economia e Finanças Públicas - publicará a Revista do Serviço Público a "Operação Guanabara" trabalho de vulto que teve uma repercussão extremamente favorável, elaborado por uma Equipe de Economistás e Técnicos de Administração, sob a oriantação do Prof. Araujo Cavalcanti. (Nota da Redação)

Sumário: Situação Atual. Condiçóes e Perspectivas do Serviço de Documentação: Panorama Geral das Dificuldades. Reorganização Urgente e Esquema de um Programa de Trabalho. Sobrevivência e Modernização do Serviço de Documentação da Secretaria-Geral de Administração do Estłado da Guanabara. (1960).

\section{$\mathrm{O}$}

SERviço de Documentação não tem acompanhado, nestes últimos anos, o ritmo de crescimento dos demais Órgãos e Serviços integrantes da Administração Estadual. Na verdade, as atividades dêsse Órgão da Secretaria-Geral de Administração do Estado da Guanabara, vêm sofrendo um processo de desintegração e progressiva redução a proporções cada vez mais insignificantes. Definhando e perdendo substância, de ano para ano, encontra-se, no momento, o Serviço de Documentação adstrito à simples manutenção, nas mais precárias condiçôes possiveis, de uma Biblioteca e de Fichários de Legislação. No que se refere ao Setor de Publicações, as iniciativas do Serviço de Documentação resume-se na eventual confecção de uma "Lista de Telefones" das principais repartições da Administraçã̃o Estadual e elaboração do "Boletim" cuja impressão está, pràticamente suspensa, desde 1948. A ausência de um Programa de Trabalho, mesmo modesto, contribui para acentuar a impressão desoladora de estagnação e decadência de um Serviço todavia indispensável e merecedor do máximo apoio.

2 Nas atuais circunstâncias, a organização interna do Serviço de Documentação é a mais rudimentar que se possa imaginar. As atribuições e responsabilidades do Órgão encontram-se empìricamente distribuídas em função das seguintes atividades: I - Fichários da Legislação; II - Biblioteca; III - Publicações e IV - Serviços Administrativos. Para as tarefas e encargos materiais decorrentes da realização dessas atividades, dispõe o Serviço de Documentação de uma reduzida Equipe de 13 funcionários dos quais apenas 5 trabalham efetivamente: - os demais servidores em número de 8 , ou estão em gôzo de férias regulamentares, ou prestam colaboração a outros Setores da Administração, como é o caso, por exemplo, de 4 servidores recentemente requisitados pela Justiça Eleitoral. O Serviço de Documentação tem urgente necessidade de pessoal técnico no tocante a biblioteconomia, à documentação, à divulgação, à execução de trabalhos datilográficos e ao arquivo. Será impossivel pretender elevar a curto prazo, os coeficientes de produtividade do Serviço de Documentação sem um mínimo 
de pessoal profissionalmente bem qualificado para o eficiente desempenho das atribuições especializadas caracteristicas do Serviço.

3 A estrutura e o funcionamento do Serviço de Documentação sofrem o impacto - como é natural - da carência absoluta de pessoal habilitado, de instalações adequadas, de recursos financeiros e de assistência técnica. Basta que se diga que o Slerviço de Documentação foi instalado em local impróprio, funcionando em uma sala pequena, com cêrca de 42 metros quadrados. Evidentemente, as exíguas dimensões dessa dependência não permitem acomodar satisfatòriamente o pessoal, os móveis e equipamentos do Serviço. Amontoam-se, de maneira sumamente incoveniente, numa área insignificante, armários, estantes, fichários, mesas, cadeiras, livros e variados objetos. Em determinadas ocasiões, a movimentação natural dos servidores, as freqüentes solicitações dos clientes da Biblioteca, o funcionamento quasi ininterrupto dos telefones, o ruido das máquinas de escrever, tornam pràticamente inviável qualquer trabalho intelectual, notadamente quando se trata da redação de algum documento que porventura exija um mínimo de estudo, concentração mental e silêncio. Problemas que estão reclamando solução imediata, a precariedade, insuficiência e inadequação das instalações, recursos e aparelhamento do Serviço de Documentação, constituem fatôres adversos e obstáculos que anulam quaisquer propósitos de reorganização. As tenta tivas de reforma do Serviço de Documentação, visando à racionalização das suas atividades, à sua modernização e aperfeiçoamento, sòmente terão possibilidades de êxito integral na hipótese em que promovam a solução prioritária dos mencionados problemas, buscando para os mesmos, soluções concretas e práticas. Acresce, ainda, salientar, a participação, por assim dizer, simbólica, do Serviço de Documentação, no Orçamento Geral do Estado da Guanabara, em virtude da insignificância dos recursos financeiros que lhe são atribuidos, no montante irrisório de $\operatorname{Cr} \$ 440.000,00$ para sua manutenção e funcionamento, aquisição de material, publicações, instalações, reparos, assinaturas de órgãos oficiais e livros destinados à Biblioteca etc.

4 Relegado a uma posição de injustificável inferioridade nos quadros da Administração Estadual; desprovido de recursos financeiros e de assistência técnica; funcionando com pessoal inabilitado, sem preparo profissional, treinamento de qualquer espécie ou, mesmo, vocação para as funções substantivas e típicas de documentação, divulgação, informações, biblioteconomia, estatística administrativa e relações públicas: - inteiramente desatualizado - êsse é o panorama atual do Serviço de Documentação cuja direção me foi confiada, a 2 de junho do corrente, pelo Secretário-Geral de Administração do Estado da Guanabara, Dr. Antônio Barsante dos Santos.

\section{REORGANIZAÇÃO E PROGRAMA DE TRABALHO DO SERVIÇO DE DOCUMENTAÇÃO}

5 No Relatório sucinto encaminhado pelo Chefe do Serviço ao Secretário-Geral de Administração a 6 de junho p. passado, estão caracterizadas as atribuições, necessidades, problemas e perspectivas do Serviço de Documentação. Como não podia deixar de ser, a conclusão básica dêsse Documento reafirma o imperativo de uma reorganização urgente e completa do Serviço 
de Documentação, a fim de que êsse Órgão da Secretaria-Geral possa prestar ao Estado da Guanabara, aos seus quadros de servidores e ao povo carioca, em geral, os variados e importantes serviços para que foi criado e que justificam a sua existência. Duas tentativas de reorganização do Serviço de Documentação foram levadas a efeito, respectivamente em dezembro de 1945 e em dezembro de 1959, pelos Drs. Joel Ruthenio de Paiva e Carlos Eduardo de Oliveira Valle, então Secretários-Gerais de Administração do Distrito Federal. Com base nos levantamentos, estudos e projetos realizados tendo em vista a solução do problema em função das conveniências e interêsses iniediatos da Secretaria-Geral de Administração, o Serviço de Documentação deve ter uma nova estrutura consubstanciada nos seguintes Setores:

a) Biblioteca;

b) Setor de Documentação Administrativa;

c) Setor de Publicações e Divulgação;

d) Setor de Estatistica Administrativa;

e) Setor de Orientação, Informações e Reclamações;

f) Setor Administrativo;

g) Revista de Administração do Estado da Guanabara.

6 A nova estrutura resulta da necessidade de melhor definir as atribuições, sistematizar as atividades e elevar os niveis de eficiência do Serviço de Documentação. Ela decorre da própria experiência de funcionamento dêsse Órgão da Secretaria-Geral de Administração - instituído pelo Decreto n? 9.603, de 17 de fevereiro de 1949 - e corresponde a um legítimo imperativo de sobrevivência das atividades de documentação e divulgação.

\section{BIBLIOTECA}

7 "A Biblioteca compete: I - adquirir, classificar, registrar, catalogar, guardar, conservar e permutar obras nacionais e estrangeiras de interêsse para a administração do Estado da Guanabara; II - Promover, através do serviço de referência e empréstimo, a utilização das coleções reunidas; III manter permanente articulação com a Escola Estadual de Serviço Público a fim de facilitar o empréstimo de livros aos alunos dos diversos Cursos e atender as necessidades especificas daquele Órgão.

$\S 1^{\circ}$ A Biblioteca será franqueada a tôda e qualquer pessoa, independentemente de quaisquer formalidades.

§ 2 . O empréstimo de publicações obedecerá às "Instruções de Serviço"

$\S 3^{\circ}$ Cabe ao Chefe da Biblioteca determinar quais as publicações que poderão circular por empréstimo e dilatar ou diminuir o prazo de empréstimo de certas publicações, de acôrdo com as conveniências do Serviço de Documentação". 


\section{DOCUMENTAÇÃO ADMINISTRATIVA}

8 "O Setor de Documentação Administrativa tem como finalidade: I - coligir, classificar e conservar a documentação referente ao Estado da Guanabara, em geral, e à Secretaria-Geral de Administração em particular, necessária ao estudo e orientação dos problemas de administração; II organizar e manter os Fichários de Legislação geral e da jurisprudência firmada em despachos, resoluções ou atos do Governador do Estado e dos Secretários-Gerais; III - manter em perfeitas condições de eficiência e permanentemente atualizados o Arquivo Documentário e o Ementário de Leis e Atos; IV - acompanhar a tramitação, na Assembléia Legislativa do Estado, dos projetos de interêsse para a Secretaria-Geral de Administração: $\mathrm{V}$ - coligir os dados necessários à elaboração do Relatório Anual da Secretaria-Geral de Administração; V - elaborar originais destinados à publicação".

\section{PUBLICAÇÕES E DIVULGAÇÃo}

9 "Ao Setor de Publicações e Divulgação compete: I - imprimir ou promover a impressão de trabalhos ou quaisquer publicações do Serviço de Documentação; II - rever os originais que por sua iniciativa devam ser impressos e as respectivas provas tipográficas; III - preparar, editar, expedir e divulgar o Boletim do Pessoal e a Revista de Administração do Estado da Guanabara".

\section{ESTATÍSTICA ADMINISTRATIVA}

10 "O Setor de Estatística Administrativa tem como finalidades: I proceder à coleta, apuração, crítica e interpretação da estatística administrava relativa à Secretaria-Geral de Administração e demais Órgãos do Estado da Guanabara; II - elaborar e encaminhar ao Setor de Publicações e Divulgação e informações periódicas de análise estatística de interêsse para a administração estadual.

\section{ORIENTAÇÃO, INFORMAÇÕES E RECLAMAÇÕES}

11 "Ao Setor de Orientação, Informações e Reclamações incumbe: I - prestar informações ao público a respeito dos problemas e assuntos peculiares à Secretaria-Geral de Administração; II - atender a reclamações e encaminhá-las para solução adequada no que se refere às atividades da Secretaria-Geral de Administração; III - receber queixas, sugestões e reclamações que digam respeito aos serviços prestados e assuntos da SecretariaGeral de Administração resumindo as e encaminhando-as ao Secretário-Geral de Administração.

\section{ADMINISTRAÇÃO GERAL}

12 "Ao Setor Administrativo compete prestar os serviços de administração geral que se fizerem necessários à execução dos objetivos, atividades e trabalhos do Serviço de Documentação, notadamente no tocante às comunicações, pessoal, material, orçamento e mecanografia. 


\section{REVISTA DE ADMINISTRAÇÃO}

13 "À Revista de Administração do Estado da Guanabara compete divulgar matéria doutrinária, informativa, crítica, noticiosa e de qualquer outro gênero que contribua para o desenvolvimento cultural e aperfeiçoamento técnico do Estado da Guanabara, no campo da Administração; II - promover investigações, pesquisas ou estudos especiais de interêsse para o Estado da Guanabara; III - organizar e realizar, o Concurso Anual de Monografias, distribuindo prêmios aos melhores trabalhos classificados; IV - manter articulação permanente e efetiva colaboração com a Escola Estadual de Serviço Público divulgando as atividades e trabalhos dêsse Órgão.

14 O Chefe do Serviço dz Documentação terá um Assessor Técnico que lhe será diretamente subordinado.

Reorganização Geral: - Imperativo de Sobrevivência do Serviço de Documentação.

15 Limitando as suas atividades à simples manutenção de rotinas obsoletas no concernente à organização de fichários de legislação, conservação de livros e elaboração de uma "Lista de Telefones", o Serviço de Documentação não dispõe de um Programa de Trabalho. Em tôda a sua existência jamais cuidou de mordenizar as rotinas, de execução dos serviços ou estabelecer um Calendário de encargos, prazo, metas ou simples esquemas para as tarefas que lhe são especificas: - a verdade é que implantou-se uma tradição de negligência, empirismo e improvisação que urge erradicar, como condição preliminar de sobrevivência do Serviço de Documentação. Programas mínimos de treinamento interno; cursos rápidos; conferências; reuniões; articulações com os Órgãos e Instituições vinculadas à biblioteconomia, documentação e relações públicas; entrosamento com os jornais e radioemissoras - em resumo, ignora-se qualquer iniciativa do Serviço de Documentação nessa área, atribuindo-se a omissão, sobretudo, à inexistência de dotações orçamentárias.

Sem uma reforma integral e urgente, o Serviço de Documentação prosseguirá na sua trajetória de autêntica "ficção burocrática", impossibilitado de atender aos interêsses, conveniências e determinações da Secretaria-Geral de Administração. Com a reorganização ora proposta serão anulados os fatôres adversos e superadas as dificuldades que têm impedido o funcionamento satisfatório do Serviço de Documentação. Para êsse fím cumpre dar início à execução de um Programa de Trabalho destinado a modernizar, aperfeiçoar e dinamizar as atividades de documentação, divulgação. estatística administrativa e relações públicas no campo da Administração Estadual.

ESQUEMA DE UM PROGRAMA DE TRABALHO

16 O Programa de Trabalho ora sugerido, embora esquemático, abrange exclusivamente as providências mais urgentes a serem posta em prática, dentro das possibilidades do Serviço de Documentação destacadas, pela sua urgência, as seguintes prioridades:

I - Reexame e Atualização do Projeto de Reorganização do Serviço de Docımentação. Implantação Gradual das Reformas Necessárias (Trabalho a ser realizado em colaboração com o Serviço de Planejamento). 
II - Levantamento das Condições da Biblioteca, Balanço Geral e Exame do Acervo: Implantação de Novas Rotinas principalmente no que se refere ao Tombamento, Classificação, Catalogação, Contrôle de Empréstimos e Consultas de Livros.

III - Atualização do Arquivo Documentário e do Ementário de Leis. A Documentação Básica de Interêsse do Estado da Guanabara.

IV - Organizar, elaborar, publicar e divulgar: 1) A Revista de Administração do Estado da Guanabara; 2) O indicador da Organização Administrativa do Estado da Guanabara; 3) Uma Coleção de Estudos e Monografias dedicadas aos Problemas Fundamentais do Estado da Guanabara - administração, economia, finanças, turismo, e assim sucessivamente - em colaboração com Órgãos e Serviços das diversas Secretarias de Estado. Estabelecimento de uma Escala de Prioridade para os Estudos a serem publicados. Rigorosa Seleção dos Técnicos ou Autoridades incumbidas da elaboração dos Estatutos Programados. Iniciar a Coleção com Trabalhos às Atividades da Secretaria Geral de Administração - Problemas de pessoal, organização, orçamento e assuntos correlatos.

$\mathrm{V}$ - Manter Entendimentos e Realizar Convênios ou Acôrdos de Colaboração e Assistência, com:

a) o Instituto Brasileiro de Bibliografia e Documentação - I.B.B.D. - do Conselho Nacional de Pesquisas;

b) com os Serviços de Documentação do D.A.S.P., dos Ministérios e Órgäns da Presidência da República;

c) com a Escola de Serviço Público e os Cursos de Administração do Estado e da União.

VI - Promover a realização de uma Série de Conferências e Palestras sôbre os Problemas Básicos de Govêrno e Administração do Estado da Guanabara a cargo de personalidades especialmente convidadas pelo Secretário-Geral de Administração. Entendimentos com Jornais e Radioemisso. ras para a mais ampla divulgação possível das Conferências e Palestras programadas.

VII - Implantar o Setor de Orientação, Informações e Reclamações - atividades estas de grande interêsse para a Administração e para os Contribuintes, em particular. Atender às Consultas formuladas.

VIII - Instalar a Sala de Imprensa. Manter Relações Permanentes e Cordiais com os Jornais e Radioemissoras, fornecendo-lhes, com regularidade, informações, notícias, artigos etc., sôbre assuntos de interêsse da Administração e do Serviço de Documentação.

IX - Instituir um Concurso Periódico de Reportagens, premiando os melhores Trabalhos apresentados a respeito dos Problemas. Órgãos e Serviços do Estado da Guanabara. Convocar, para êsse fim, os Jornalistas credenciados pelo Secretário-Geral de Administração. 


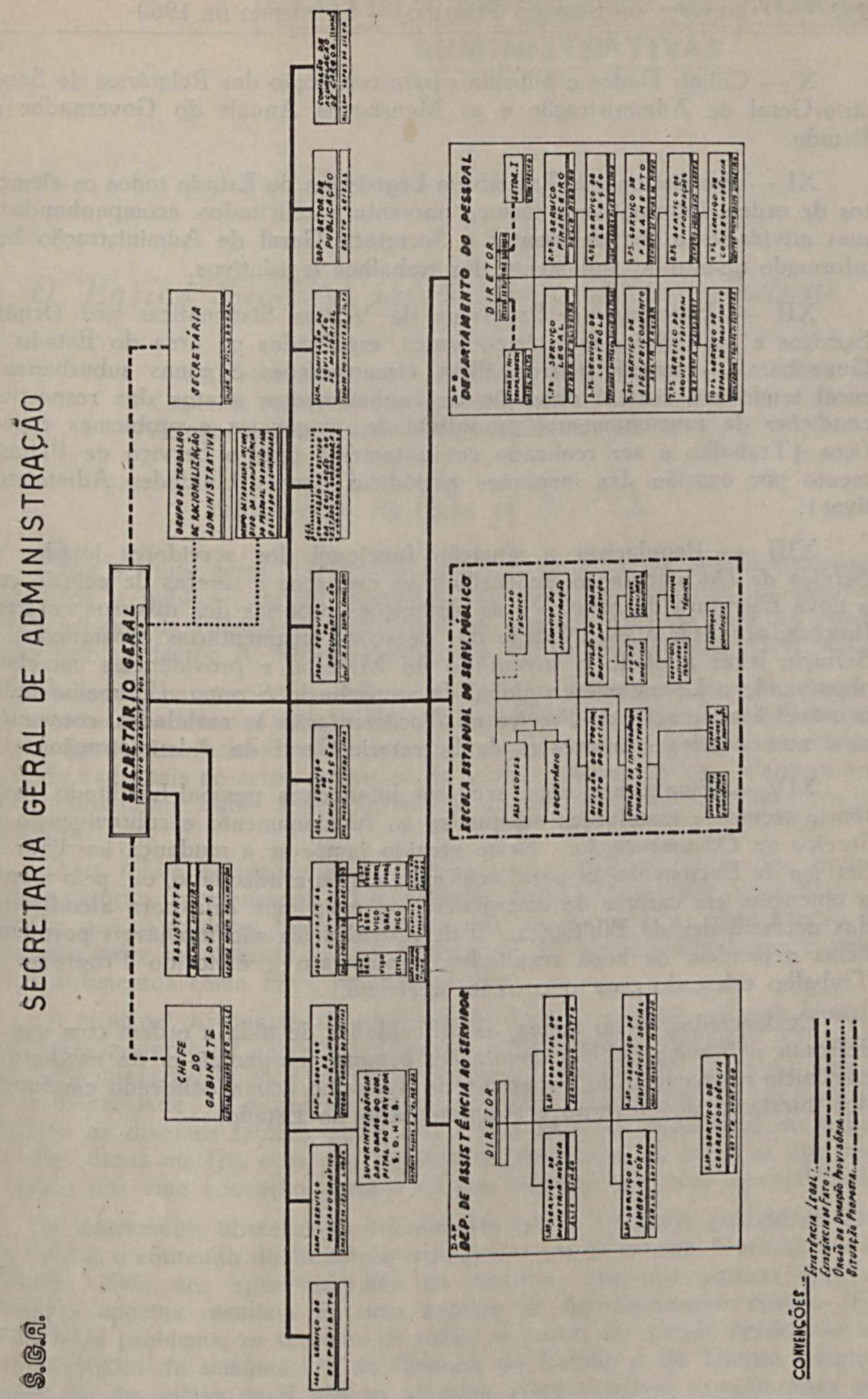


X - Coligir Dados e Subsidios para confecção dos Relatórios do Secretário-Geral de Administração e as Mensagens Anuais do Governador do Estado.

XI - Proporcionar à Assembléia Legislativa do Estado todos os elementos de ordem informativa e técnica porventura solicitados. acompanhando as suas atividades a fim de manter o Secretário-Geral de Administração bem informado quanto ao andamento dos trabalhos legislativos.

XII - Executar um Programa de Visitas Sistemáticas aos Órgãos, Serviços e Instituições mais importantes, espalhados na área do Estado da Guanabara - centro, bairros, ilhas, circunscrições e zonas suburbanas e rural tendo em vista a obtenção de conhecimentos exatos das respectivas condições de funcionamento; produtividade, exigências e problemas especificos (Trabalho a ser realizado conjuntamente com o Serviço de Planejamento por ocasião das inspeções periódicas dessas Unidades Administrativas).

XIII - Regularizar a situação funcional dos servidores lotados no Serviço de Documentação; redistribuir os encargos e tarefas de acôrdo com a nova Estrutura do Serviço e as atribuições próprias dos diversos cargos e funções; atualizar a escrituração das dotações orçamentárias consignadas ao Serviço; levar a efeito o Inventário do Material e providências correlatas objetivando o Levantamento global da situação do Serviço. (Trabalho indispensável à adaptação do Serviço de Documentação às realidades, conveniências, necessidades e interêsses da Secretaria-Geral de Administração).

XIV - Finalmente, obter recursos financeiros, pessoal habilitado, assistência técnica e instalações adequadas ao funcionamento e sobrevivência do Serviço de Documentação. Neste sentido impõe-se a mudança imediąia do Serviço de Documentação para local mais amplo e adequado, ou, pelo menos, a obtenção, em caráter de emergência, de mais uma sala para atendimento das necessidades da Biblioteca. Tais providências são inadiáveis porquanto delas dependem os bons resultados, rendimento e êxito do Programa de Trabalho esboçado para o corrente exercício.

Evidenciadas, desta forma, as dificuldades de tôda a ordem com que se defronta o Serviço de Documentação, cumpre reorganizá-lo. de imediato, e dar inicio a execução do Programa de Trabalho acima delineado em função dos interêsses do Govêrno e Administração do Estado. 